\title{
Aluminum Phosphate Catalyzed Free Solvent Preparation of $\beta$-enamino Esters
}

\author{
Mohamed Anouar Harrad, Brahim Boualy, Larbi El Firdoussi, Mustapha Ait Ali \\ Université Cadi Ayyad Facuté des Sciences Semlalia, Equipe de Chimie de Coordination et Catalyse, Departement de Chimie BP 2390, \\ 40001, Marrakech, Morocco
}

\begin{abstract}
Aluminum phosphate $\left(\mathrm{AlPO}_{4}\right)$ efficiently catalyzed the condensation of 1,3-ketoesters with primary amines under free solvent conditions. The catalyst has been prepared and characterized by powder XRD and FT-IR studies. The $\mathrm{AlPO}_{4}$ synthesis was performed in water at room temperature from $\mathrm{AlCl}_{3}$ and $\mathrm{H}_{3} \mathrm{PO}_{4}$ in the presence of ammonia solution. Resultant material showed good catalytic efficiency in condensation of 1,3-ketoesters with primary amines using a domestic micro wave oven with no solvent. The reaction was complete in $7 \mathrm{~min}$ to afford $\beta$-enamino esters in a high yield and high selectivity.
\end{abstract}

Keywords $\beta$-enamino Esters, Micro wave, Solvent Free Conditions, $\mathrm{AlPO}_{4}$

\section{Introduction}

$\beta$-enaminones are important intermed iates in the synthesis of natural products[1] and heterocyclic compounds[2,3] . Anticonvulsive activity of several secondary enaminones has been reported[4]. A number of methods have been described for the preparation of $\beta$-enamino carbonylic compounds [5-8], such as condensation of amines with $\beta$-dicarbonylic compounds in aromatic solvents with azeotropic water removal[9] or Raney-Ni hydrogenation of isoxazoles[6]. However, these methods require high pressure and temperature[10]. The use of low boiling amines is particularly problematic. Consequently, various modified synthesis methods have been reported, in particular the addition of amide enolates[11]. Improved procedures have been reported which use protic acids such as PTSA (para-toluene sulfonic acid)[12], and Lewis acids such as $\mathrm{BF}_{3}-\mathrm{OEt}_{2}[13], \mathrm{Mg}\left(\mathrm{ClO}_{4}\right)_{2}[14], \mathrm{Bi}(\mathrm{OTf})_{3}[15], \mathrm{Sc}(\mathrm{OTf})_{3}[16]$.

As part of our work on the synthesis and reactivity of $\beta$-enaminoesters in heterogeneous media[17-19], we report here a simple and fast procedure for the synthesis of these compounds under solvent-free conditions using $\mathrm{AlPO}_{4}$ as catalyst and a domestic microwave oven. Aluminum phosphate is of great interest in environmental, technological fields[20-27] and catalytic reactions [21-27]. It can be easily prepared by means of a sol-gel protocol[28-35]. The prepared $\mathrm{AlPO}_{4}$ Materials have high density of Brönsted acid sites making them particularly suitable as heterogeneous catalysts for different organic synthesis reactions [34-35].

* Corresponding author:

aitali@uca.ma (Mustapha Ait Ali)

Published online at http://journal.sapub.org/chemistry

Copyright (C) 2012 Scientific \& Academic Publishing. All Rights Reserved
The use of microwave irradiation in the presence of catalysts or mineral-supported reagents, under solvent-free conditions[36], provides a simple chemical process with special attributes such as enhanced reaction rates, higher yields, greater selectivity and ease of manipulation[37].

\section{Experimental}

\subsection{Instruments}

NMR studies were performed on a Bruker Advance 300 spectrometer in $\mathrm{CDCl}_{3}$. chemicals shifts are given in ppm relative to external TMS and coupling constant $(\mathrm{J})$ in $\mathrm{Hz}$. Infrared spectra (IR) were obtained on a Bruker-TENSOR 27 spectrometer instrument. X-ray diffraction patterns (XRD) were obtained with a Philips X'Pert MPD diffractometer using $\mathrm{Cu}$ Ka radiation $(\mathrm{k}=1.54178 \AA)$. Mass spectra were recorded on a GC-MS Varian star 3400 CX. Optical rotation was measured at room temperature using an ATAGO polax-D polarimeter. Microwave irradiations were carried out in a domestic micro wave oven Model AVM 510/WP/WH $(700 \mathrm{~W})$. The products' physical and spectroscopic data were compared with those reported in the literature.

\subsection{Synthesis of $\mathrm{AlPO}_{4}$}

In a $100 \mathrm{~mL}$ three-neck round bottom flask, $\mathrm{AlCl}_{3} \cdot 6 \mathrm{H}_{2} \mathrm{O}$ (7.5 mmol), and $4 \mathrm{~mL}$ of $\mathrm{H}_{3} \mathrm{PO}_{4}(37 \%)$ are introduced dropwise with stirring at room temperature[28-35]. A fter 30 min, $2.3 \mathrm{~mL}$ of ammonia solution (24\%) was added dropwise to precipitate aluminum phosphate at a $\mathrm{pH}$ of 9.0. The precipitate was filtered and washed with distilled water. The resulting product was recrystallized in methanol. The white solid was filtered, washed with Methanol and dried at $120^{\circ} \mathrm{C}$ over night. 


\subsection{Procedure of Catal ytic Studies}

In a typical experiment $1.7 \mathrm{mmol}$ of ketoester, $1.7 \mathrm{mmol}$ of amines and $0.17 \mathrm{mmol}$ of $\mathrm{AlPO}_{4}$ were used, the heterogeneous mixture was transferred to a microwave oven at $60 \mathrm{~W}$ for the time indicated in Table 1 . At the end of the reaction, $10 \mathrm{~mL}$ of distilled water were added to the residue and extracted with diethyl ether $(3 \times 25 \mathrm{~mL})$. The organic layer was dried over $\mathrm{Na}_{2} \mathrm{SO}_{4}$, and the solvent was removed under vacuum. Pu re $\beta$-enamioesters was obtained by column chromatography over silica gel using hexane/ethyl acetate as eluent. All isolated pure products were fully characterized by ${ }^{1} \mathrm{H},{ }^{13} \mathrm{C}$ NMR and Mass spectra compared with the known compounds[17].

\section{Results and Discussion}

\subsection{Catalyst Characterization}

Structural properties of the prepared $\mathrm{AlPO}_{4}$ were characterized using FT-IR and XRD analysis.

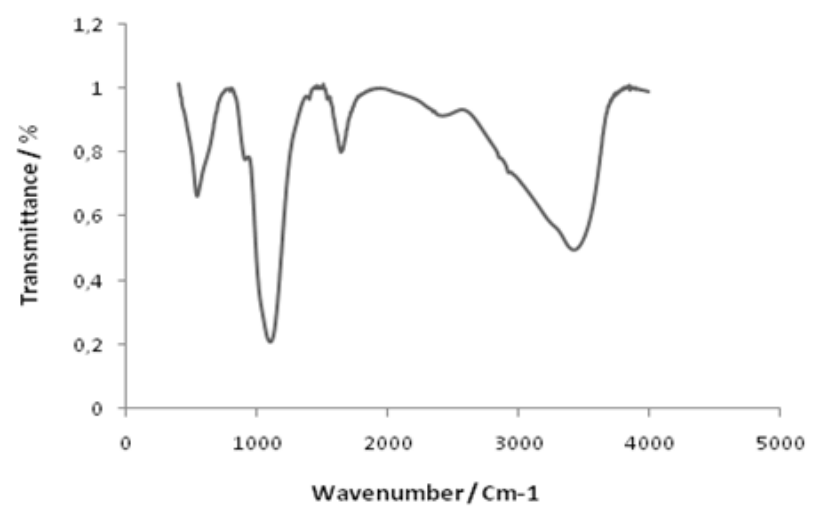

Figure 1. FT-IR spectra of prepared $\mathrm{APO}_{4}$

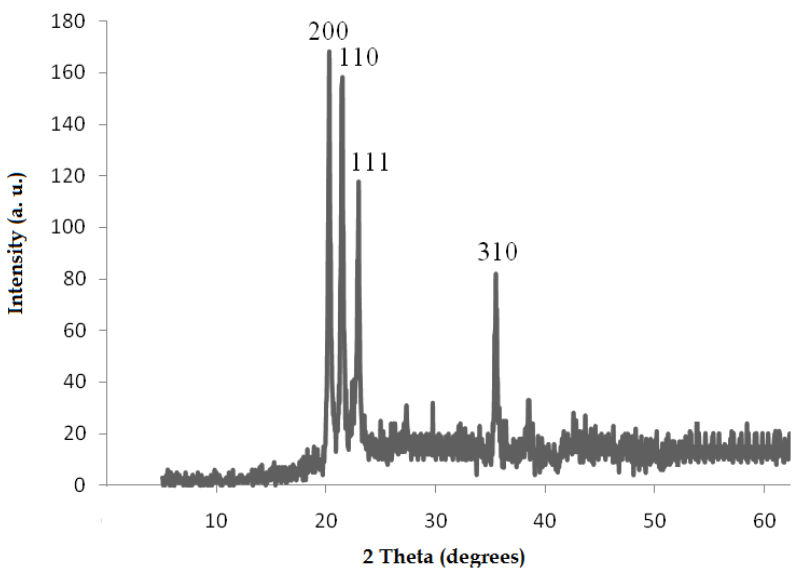

Figure 2. The XRD patterns of obtained $\mathrm{AlPO}_{4}$

A FT-IR spectrum of prepared $\mathrm{AlPO}_{4}$ is shown in Fig. 1. Vibrational bands are identified in relation to the crystal structure in terms of the fundamental vibrating units, namely $\mathrm{PO}_{4}{ }^{3-}, \mathrm{H}_{2} \mathrm{O}[38-40]$. FTIR spectra of $\mathrm{PO}_{4}{ }^{3-}$ in $\mathrm{AlPO}_{4}$ show the antisymmetric stretching mode $\left(v_{3}\right)$ in $1000-1200 \mathrm{~cm}^{-1}$ region and the $v_{4}$ mode in $400-560 \mathrm{~cm}^{-1}$ region. The observed bands in $1600-1700$ and $3000-3500 \mathrm{~cm}^{-1}$ region are attributed to the water bending and stretching vibrations, respectively[40]. These water bands confirmed that the product is in hydrate form $\mathrm{AlPO}_{4} \mathrm{xH}_{2} \mathrm{O}$.

XRD pattern of the synthesized $\mathrm{AlPO}_{4}$ powder samples showed that all peak positions and relative peak intensities of $\mathrm{AlPO}_{4}$ matched well with those of the standard XRD pattern. All the diffraction peaks orientated along (200), (110), (111) and (310) correspond to the well-crystalline monoclinic $\mathrm{AlPO}_{4}$ phases (JCPDS Card No. 00-051-1674) as observed from Fig. 2.

\subsection{Catalyst Activity Studies}

In a typical experiment, equimolar ratio of ketoester and primary amine were mixed in the presence of a catalytic amount of $\mathrm{AlPO}_{4}(10 \mathrm{~mol} \%)$ without solvent to obtain the corresponding enaminoester in good yields (Table 1). The reaction was completed within the indicated time under microwave irradiations using a domestic microwave oven. No by-products were obtained (scheme 1).

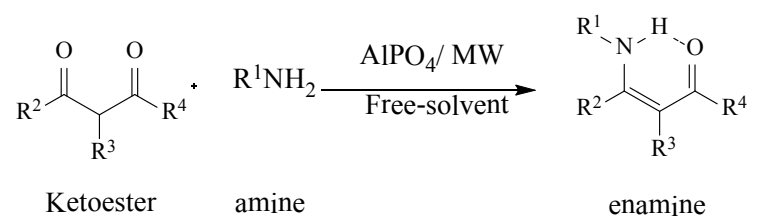

Scheme 1. Condensation of Ketoesters with primary amines

The condensation of various primary amines with ketoesters, was investigated, providing the corresponding enamino esters in good to excellent yields. A mong these, aliphatic amines were more reactive and gave the corresponding $\beta$-enamino ester in excellent yields 95\%-98\% (Table 1, entries 1-5). This protocol efficiently condensed anilines having electron donating groups in position 4 (e.g., F, $\mathrm{Br}, \mathrm{Me}$ and $\mathrm{OMe}$ ) with ketoesters to produce the corresponding $\beta$-enamino esters in excellent yields (Table 1 , entries 8-9, 11-12), whereas in the presence of electron withdrawing group $\left(\mathrm{NO}_{2}\right)$ a high decrease in the yield was observed (Table 1, entry 10). In the presence of amines possessing sterically hindering groups on the aromatic rings, the process required longer time (6 to $7 \mathrm{~min}$ ) to obtain reasonable yield (Table 1, entries 13,15 ) when compared to other amines.

Under the same reaction conditions, the condensation of naphthylamine and ketoester affords the corresponding $\beta$-enaminoester in a moderate yield after 7 min (Entry 16).

It is noteworthy that optically active amine was converted into the corresponding $\beta$-enamino ester 6 without any racemization. The optical rotation was found to be $[\alpha]_{D}{ }^{20}=$ $-623, \mathrm{c}=1.25$, in EtOH matched the literature values (entry 6) [41-42].

The reaction proceeds cleanly leading to formation of the pure product as determined by chromatography, avoiding any tedious work up. The stereoselectivity of the reaction is confirmed by ${ }^{1} \mathrm{H}$ NMR spectra. The signal of the $-\mathrm{NH}-$ group appearing at a lower field $(\delta>8.2 \mathrm{ppm})$ indicated the formation of an intramolecular hydrogen bond, which stabilized the enamines as a (Z) configuration[17-19] (Scheme 1). 
Table 1. Synthesis of $\beta$-enaminoesters using $\mathrm{AIPO}_{4}$ assisted by MW under solvent free conditions

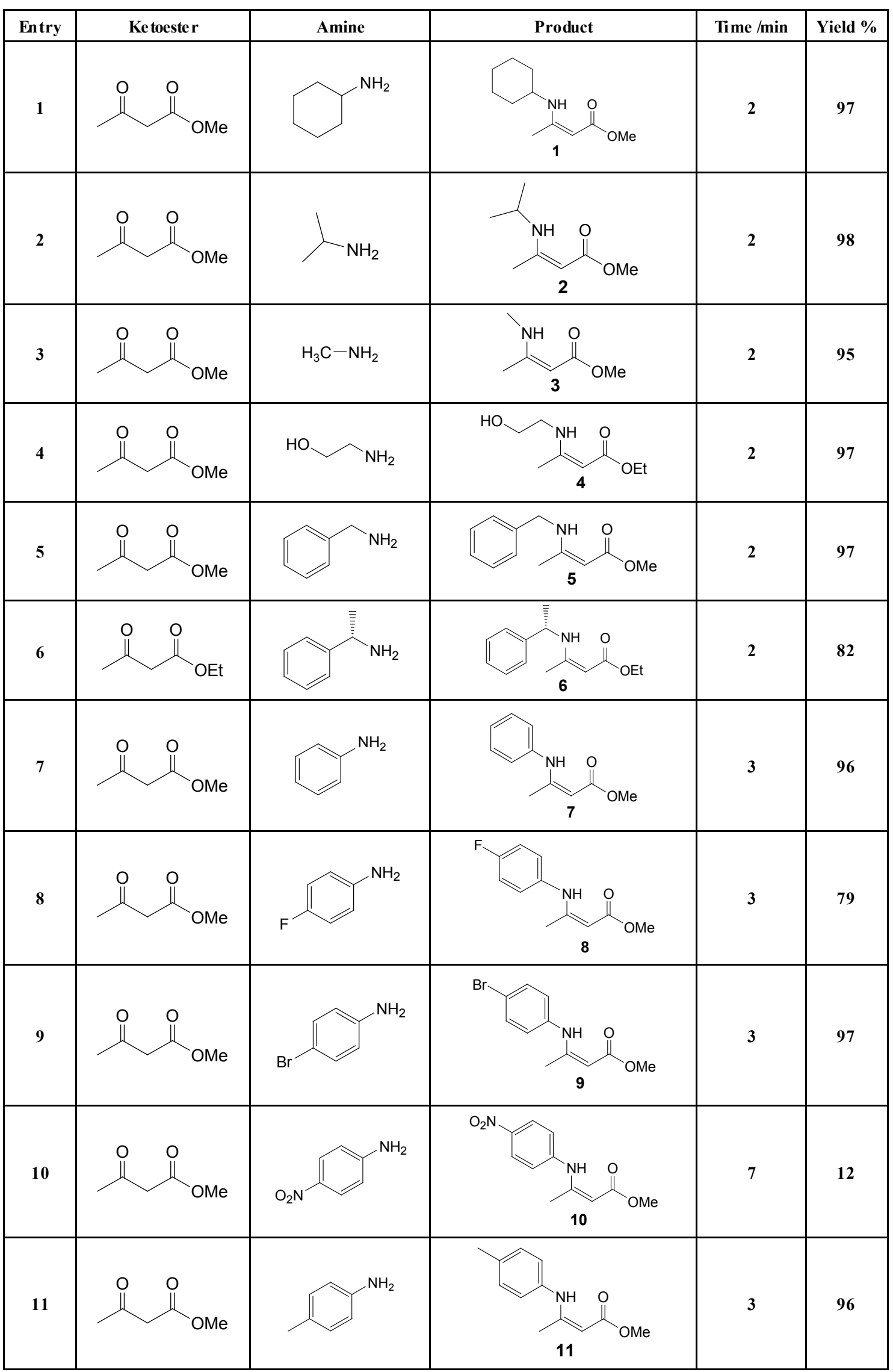




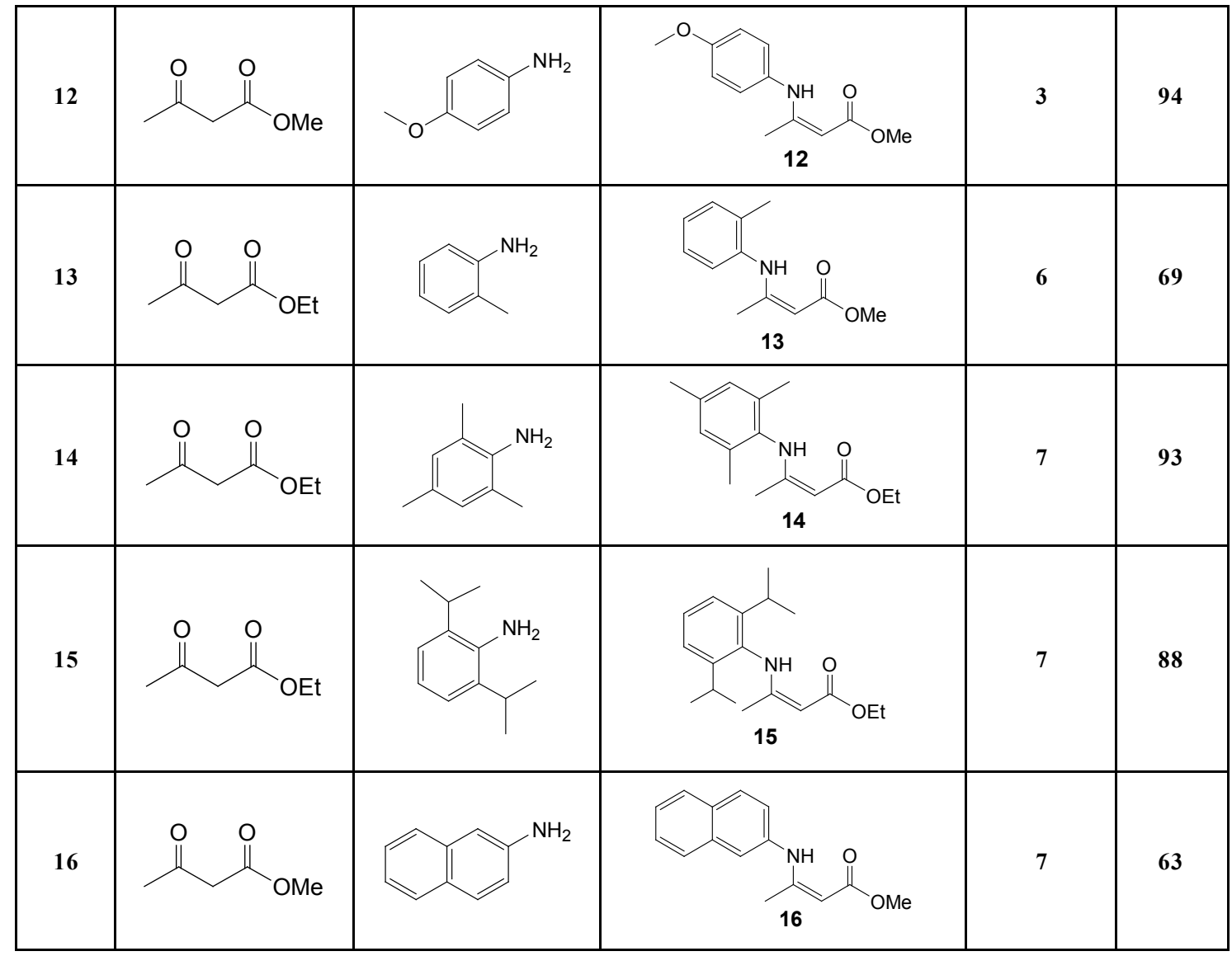

Conditions: ketoester $(1.7 \mathrm{mmol})$; amines $(1.7 \mathrm{mmol}) ; \mathrm{AlPO}_{4}(0.017 \mathrm{mmol})$

\section{Conclusions}

Microwave irradiation in solvent-free conditions of primary amines and ketoesters using $\mathrm{AlPO}_{4}$ as catalyst leads to the formation of $\beta$-enaminoesters compounds in good to excellent yields. The reaction employs a simple catalytic system resulting in shorter reaction time than the conventional procedure. The advantages of the novel and facile methodology are precluding volatile, clean process, economic and environmental procedure.

\section{ACKNOWLEDGMENTS}

We thank Pr. A. Lachgar (Wake Forest University Winston-Salem, USA) for his interest to this work and for his helpful discussion.

\section{REFERENCES}

[1] Michael JP, de Koning CB, Gravestock D, Hosken GD, Howard AS, Jungman CM, Krause RWM, Parsons AS, Pelly SC, Stambury TV. Enaminones: versatile intermediates for natural product synthesis. Pure Appl Chem, 71, 979-988 1999.

[2] Greenhill JV, Chaaban I, Stell PJ. Functionalised enaminones and their use in heterocy clic synthesis. J Heterocycl Chem, 29, 1375-1383, 1992.

[3] Kubicki, M.; Cunha S, Rodovalho W, Azevedo NR, Mendonça MO, Lariucci C, Vencato I. The Michael Reaction of Enaminones with N-(p-tolyl)-maleimide: Synthesis and Structural Analy sis of Succinimide-enaminones. J Braz Chem Soc, 13, 629-634, 2002.

[4] Bassyouni HAR, Codding PW. Hydrogen bonding in three anticonvulsant enaminones. J Mol Struct, 525, 141-152, 2000 .

[5] Hugo TSB, Mara EFB, Giovanni BR, Daniela AO. Preparation of-enamino carbonylic compounds using microwave radiation/K-10. J Braz Chem Soc. 14, 994-997, 2003.

[6] Yuanhong Z, Jingfeng Z, Yongyun Z, Ze L, Liang L, Hongbin $Z$. Efficient synthesis of $\beta$-amino- $\alpha, \beta$-unsaturated carbonyl compounds. New J Chem. 29, 769-772, 2005.

[7] Zhan-Hui Z, Jin-Yong H. Cobalt(II) chloride-mediated synthesis of-enamino compounds under solvent-free conditions. J Braz Chem Soc. 17, 1447-1451, 2006.

[8] Bhatte KD, Tambade PJ, Dhake KP, Bhanage BM. Silver nanoparticles as an efficient, heterogeneous and recyclable catalyst for synthesis of $\beta$ enaminones. Catal Comm. 11, 1233-1237, 2010.

[9] Greenhill JV. Enaminones. Chem Soc Rev. 6, 277-294, 1977.

[10] Alberola A, Calvo LA, González-Ortega A, Sañudo Ruíz MC, 
Yustos P, García S, García-Rodríguez E. Regioselective synthesis of $2(1 \mathrm{H})$-pyridones from $\beta$-aminoenones and malonitrile. Reaction mechanism. J Org Chem. 64, 9493-9498, 1999.

[11] Hannick SM, Kishi Y. Improved procedure for the Blaise reaction: A short practical route to the key intermediates of the saxitoxin synthesis. J Org Chem. 48, 3833-3835, 1983.

[12] Elaridi J, Thaqi A, Prosser A, Jackson WR, Robinson AJ. An enantioselective synthesis of $\beta 2$-amino acid derivatives. Tetrahedron: Asymmetry 16, 1309-1319, 2005.

[13] Tefane B, Polanc S. A new regio- and chemoselective approach to -keto amides and -enamino carboxamides via 1,3,2-dioxaborinan es. Synlett. 698-702, 2004.

[14] Zhao Y, Zhao J, Zhou Y, Lei Z, Li L, Zhang H. Efficient synthesis of $\beta$-amino- $\alpha, \beta$-unsaturated carbonyl compounds. New J Chem. 29, 769-772, 2005.

[15] Khodaei MM, Khosropour R, Kookhazadeh M. A novel enamination of $\beta$-dicarbonyl compounds catalyzed by Bi(TFA) 3 immobilized on molten TBAB. Can J Chem. 83, 209-212, 2005.

[16] Yadav JS, Kumar VN, Rao RS, Priyadarshini AD, Rao PP, Reddy BVS, Nagaiah K. Sc(OTf) ${ }_{3}$ Catalyzed highly rapid \& efficient synthesis of -enamino compounds under solvent-free conditions. J Mol Catal A Chem. 256, 234-237, 2006.

[17] Harrad MA, Outtouch R, Ait Ali M, El-Firdoussi L, Karim A, Roucoux A. An efficient Lewis acid catalyst for chemo- and regio-selective enamination of $\beta$-dicarbonyl compounds. Catal Comm. 11, 442- 446, 2010.

[18] Harrad M A, Boualy B, Oudahmane A, Avignant D, Corrado R. (Z)-4-(2-Naphthy lamino)pent-3-en-2-one. Acta Cryst. E67, o1818, 2011.

[19] Harrad MA, Boualy B, Ait Ali M, El-Firdoussi L, Corrado R. rac-Ethyl (2Z)-3-\{2-[(Z)-4-ethoxy-4-oxobut-2-en-2-y lamino]cy clohex ylamino but-2-enoate. Acta Cryst. E67, o1269-o1270, 2011.

[20] Arjona MA, Alario Franco, MA. Kinetic of the thermal d'hy dratation of variscite and specific surface area of the solid decomposition products. J Therm Anal Cal. 5, 319-328, 1973.

[21] Stojakovic D, Rajic N, Sajic S, Logar NZ, Kaucic V. A kinetic study of the thermal degradation of 3-methylaminopropylamine inside $\mathrm{AlPO}_{4}$-21. J Therm Anal Cal. 87, 339-343, 2007.

[22] Lagno F, Demopoulos GP. Synthesis of Hydrated Aluminum Phosphate, $\mathrm{AlPO}_{4} \cdot 1.5 \mathrm{H}_{2} \mathrm{O} \quad\left(\mathrm{AlPO}_{4}-\mathrm{H}_{3}\right)$, by Controlled Reactive Cry stallization in Sulfate Media Ind Eng Chem Res. 44, 8033-8038, 2005.

[23] Youssif MI, Mohamed FSh, Aziz MS. Chemical and physical properties of $\mathrm{All}-\mathrm{xFexPO}$ alloys Part I. Thermal stability, magnetic properties and related electrical conductivity. Mater Chem Phys. 83, 250-254, 2004.

[24] Gutierrez-Mora F, Goretta KC, Singh D, Routbort JL, Sambasivan S, Steiner KA. High-Temperature Mechanical Behavior of Aluminum-Phosphate Based Glass Ceramics (Cerablak). J Eur Ceram Soc.26, 1179-1183, 2006.

[25] Britton A, Koch FA, Mavinic D S, Adnan A, Oldham WK, Udala B. Pilot-scale struvite recovery from anaerobic digester supernatant at an enhanced biological phosphorus removal wastewater treatment plant. J Environ Eng Sci. 4, 265-277, 2005.

[26] De Farias RF. Chemistry on modified oxide and phosphate surfaces. Interface Science and Technology. First ed. Elsevier, pp 203, 2009.

[27] Boonchom B, Youngme S, Srithanratana T, Danvirutai C. Synthesis of $\mathrm{AlPO}_{4}$ and kinetics of thermal decomposition of $\mathrm{AlPO}_{4} \cdot \mathrm{H}_{2} \mathrm{O}-\mathrm{H}_{4}$ precursor. J Therm Anal Cal. 91, 511-516, 2008.

[28] Luna D, Bautista FM, Garcia A, Campelo JM, Marinas JM, Romero AA, Llobet A, Romero I, Serrano I. method for the chemical binding of homogenous catalysts to inorganic solid supports, products thus obtained and applications of same. PCTWO 2004/096442, 2004.

[29] Bautista FM, Caballero V, Campelo JM, Luna D, Marinas JM, Romero AA, Romero I, Serrano I, Llobet A. Heterogenization of a Ru (II) homogeneous asymmetric hydrogenation catalyst containing BINAP and the N-tridentate bpea ligand, through covalent attachment on amorphous $\mathrm{AlPO}_{4}$ support. Top Catal. 40, 193-205, 2006.

[30] Bautista FM, BravoC, Campelo JM, García A, Jurado A, Luna D, Marinas JM, Romero AA. Properties of a glucose oxidase covalently immobilized on amorphous $\mathrm{AlPO}_{4}$ support. J Mol Catal B. 11, 567-577, 2001.

[31] Bautista FM, Bravo MC, Campelo JM, García A, Luna D, Marinas JM, Romero AA. Covalent immobilization of acid phosphatase on amorphous $\mathrm{AlPO}_{4}$ support. J Mol Catal B. 6,473-481, 1999.

[32] Liu G, Jia M, Zhou Z, Zhang W, Wu T, Jiang D. Synthesis of amorphous mesoporous aluminophosphate materials with high thermal stability using a citric acid route. Chem Commun. 14, 1660-1661, 2004.

[33] Braibante MEF, Braibante HS, Rosso GB, Roza JK. $\alpha$-Bromination of $\beta$-Enamino Compounds Using K-10. Synthesis.1927-1935, 2001.

[34] Caballero V, Bautista FM, Campelo JM, Luna D, Luque R, Marinas J-M, Romero AA, Romero I, Montserrat R, Serrano I, Hidalgo J-M, Llobet A. Efficient hydrogenation of alkenes using a highly active and reusable immobilised $\mathrm{Ru}$ complex on $\mathrm{AlPO}_{4}$. J Mol Catal A Chem. 308, 41-45, 2009.

[35] Ranu BC, Hajra A, Jana U. Microwave-Assisted Synthesis of Substituted Pyrroles by a Three-Component Coupling of $\alpha, \beta$-Unsaturated Carbonyl Compounds, Amines and Nitroalkanes on the Surface of Silica Gel. Synlett.75-76, 2000 .

[36] Lidström P, Tierney J, Wathey B, Westman J. Microwave assisted organic synthesis. Tetrahedron. 57, 9225-9283, 2001.

[37] Revial G, Lim S, Viossat B, Lemoine P, Tomas A, Duprat AF, Pfau M. Enantioselective Michael Reactions of Chiral Secondary Enaminoesters with 2-Substituted Nitroethy lenes. Syntheses of trans, trans-2,4-Disubstituted Pyrrolidine-3-carb oxylates. J Org Chem. 65, 4593-4600, 2000.

[38] Rokita M, Handke M, Mozgawa W. Spectroscopic studies of polymorphs of $\mathrm{AlPO}_{4}$ and $\mathrm{SiO}_{2}$. J Mol Struct. 450, 213-217, 1998. 
[39] Muller G, Bodis J, Eder-Mirth G, Kornatowski J, Lercher JA. In situ FT-IR microscopic investigation of metal substituted $\mathrm{AlPO}_{4}-5$ single crystals J Mol Struct. 410-411, 173-178, 1997.

[40] Colthup NB, Daly LH, Wiberley SE. Introduction to infrared and Raman spectroscopy. New York: Academic Pressn, p 31, 1964.
[41] Zhang ZH, Li TS, Li JJ. Synthesis of enaminones and enamino esters catalysed by $\mathrm{ZrOCl}_{2} \cdot 8 \mathrm{H}_{2} \mathrm{O}$. Catal Comm. 8, 1615-1620, 2007.

[42] Bautista FM, Campelo JM, Garcia A, Guardeno R, Luna D, Marinas JM. $\mathrm{AIPO}_{4}$-supported nickel catalysts IX. Liquid-phase selective hydrogenation of propargyl alcohols. J Catal. 125, 171-186, 1990. 